\title{
HISTÓRIA MEDIEVAL: UMA BREVE APRESENTAÇ̃̃O DO MAIS RECENTE MANUAL NACIONAL SOBRE O TEMA
}

Yuri Borges $^{1}$

SILVA, Marcelo Cândido da. História Medieval. São Paulo: Contexto, 2019. 160 p.

Da maneira como é apresentado no ensino escolar no Brasil, a Idade Média, é um período Histórico que se inicia em 476 com a queda de Roma e que termina com a de Constantinopla ou o fim da Guerra dos Cem Anos ambos os eventos em 1453. Depreciada, a ideia de Idade Média representa algo ruim na memória coletiva graças a uma cultura de desprezo produzida pelos renascentistas e perpetuada pelos iluministas. Fugindo desses preconceitos, a História, enquanto ciência apresentará este período com um novo olhar norteador (MACEDO, 2005).

É dentro deste fenômeno, que entrará a obra do professor da Universidade de São Paulo, Marcelo Cândido, História Medieval, que num formato de manual, busca trabalhar as principais características desse período, tendo como metodologia o enfoque aos contrastes, como, por exemplo, fome e prosperidade, guerra e paz, universalismo e particularismo. A obra se divide em sete capítulos sendo um introdutório, e o último com indicações bibliográficas. Com exceção do primeiro e do último, todos os capítulos são divididos em tópicos geralmente temáticos, constituindo o recorte predominante da obra, com temas menores diluídos dentro desses maiores, tornando o livro de fácil leitura para qualquer leitor. O objetivo deste artigo consiste principalmente em apresentar esta obra de maneira crítica e fazer uma breve revisão bibliográfica sobre o tema, visando entregar para o professor, estudante ou pesquisador um breve panorama sobre o livro.

Ao decorrer do livro várias fontes documentais são colocadas em quadros com os textos, assim mostrando para o leitor leigo a importância das fontes históricas, incentiva quem deseja pesquisar na área, ler, conhecer e buscar documentos utilizados pelo historiador medievalista, e também, coloca uma gama de documentos que podem ser discutidos pelo professor em sala de aula. Na Introdução (p.7-14), o primeiro capítulo deste trabalho, é justamente o momento em que este é apresentado na totalidade, suas perspectivas, horizontes e problemas no qual ao autor dá destaque a dois aspectos, o primeiro, no fato da Idade Média não ser a Idade das Trevas e os porquês deste termo estar incorreto. Já o segundo, sobre como a Idade Média,

1 Instituição: Universidade Estadual Paulista, Orcid: https://orcid.org/0000-0002-8968-4669, E-mail: yuriges@hotmail.com 
enquanto período Histórico, é uma convenção cronológica criada num contexto específico do século XIV, o Renascimento, e isso já é lugar-comum entre os historiadores.

Christian Amalvi, por exemplo, afirmará que esse longo período de mil anos que geralmente é colocado entre a conquista da Gália por Clóvis e a Guerra dos Cem Anos, é nada mais nada menos que a perpetuação de um mito, a Idade Média, não existe (AMALVI, 2017). Tanto a Idade Média, quanto o Renascimento, são termos valorativos de época, ou seja, buscam diminuir a primeira e valorizar o segundo momento.

O segundo capítulo, Mundo Romano e os Reinos Bárbaros (p. 15-42), trata principalmente do processo de integração entre romanos e "bárbaros" durante o momento que chamamos de Antiguidade Tardia, ou Primeira Idade Média, no caso de Hilário Franco Jr. (2001), que se estende do século III até o VII (Se iniciando no que tradicionalmente consideramos Idade Antiga e se estendendo até a Idade Média, mostrando a elasticidade dos períodos). Esse processo de integração, que como já dito, é comumente chamado de "Invasões Bárbaras", na prática, como mostra o capítulo, foi um longo processo que ocorrera entre os séculos IV e VI, e que apesar de alguns episódios violentos, a integração foi tamanha que a distinção entre romano e bárbaro parece ser quase nula em alguns momentos, portanto, hoje o termo mais correto se trata de "Migrações Bárbaras".

O processo de migração se torna mais intenso após o fim da crise do século III, que se tratou de uma crise geral no Império Romano, que numa perspectiva de longa duração teve como causa a Pax Romana e como consequência o nascimento do ocidente medieval. A integração bárbaro-romana não foi só grande no sentido de duração, mas também na sua complexidade, e várias formas de integração são apresentadas na obra dando destaque ao regime de federação, na qual os grupos mantinham sua organização interna e seu líder, que as vezes recebia o título de rex (rei). Os episódios violentos também são mencionados, porém, com a ressalva que geralmente, quando aconteciam, não se tratava de oposição pura e simples. A queda de Roma em 476 enquanto marco definitivo também é contestada, pois, em primeiro, as fontes contemporâneas não dão tanta importância para este fato, inclusive Ordoacro, o líder dos hérulos responsáveis pela deposição de Rômulo Augusto, enviam as insígnias imperiais para Constantinopla, respeitando a autoridade imperial. Em segundo, há uma vacância e não queda do poder do imperador que será reestabelecido através de Carlos Magno no natal de 800 .

No terceiro capítulo, A dominação senhorial (p. 43-80), vemos uma abordagem histórica do grande domínio desde sua gênese até sua dinâmica frente ao mundo urbano.

O grande domínio tem suas raízes já na França merovíngia e possui algumas semelhanças com a Villa romana, apesar de não ser uma evolução linear dessa. Com a crise do Império Carolíngio, provocada pelas suas instabilidades desde a morte de Carlos Magno como as desavenças internas após o Tratado de Verdun (840) e as invasões eslavas, normandas e muçulmanas no século IX e X, o ocidente acabará tendo que se reinventar para superar tamanhas dificuldades, nisso acabará desembocando num sistema denominado Feudalismo que vigorará entre os séculos XI e XIII (GUERREAU, 1980). Hoje, porém, o termo Feudalismo é problematizado pelos historiadores, uma vez que o "Feudo" e as relações feudo-vassálicas é algo restrito a apenas uma pequena parcela dessa sociedade complexa, pois, se trata de relações horizontais entre nobres e nobres. Já as relações senhoriais, são verticais entre nobres e servos, 
portanto, abrangendo de uma maneira mais geral este sistema, e é por isso que Cândido prefere utilizar o termo "Senhorio"2 que "Feudalismo"3 (FRANCO JÚNIOR, 1993). Será também durante os séculos XI e XIII que o grande domínio alcançara seu auge no qual o "Senhorio" passará a vigorar a todo o vapor.

Com a vacância imperial, haverá dois grandes beneficiários dessa reorganização: aristocracia e a Igreja. A primeira, com a atomização do poder intensificado no ano mil, esta aristocracia que se fundirá com a cavalaria (tornando a nobreza uma corporação de aristocratas e guerreiros de elite simultaneamente), erguerá uma série de fortalezas denominadas castelos e que tiveram como função a defesa da Cristandade contra o invasor, contra o pagão e contra o herege (FLORI, 2005).

Essas duas instituições, em determinados momentos foram antagônicas, mas especialmente nesse período, denominado de Idade Média Central ou Clássica (Séculos XI -XIII), tenderão a se complementar, sendo que num determinado momento, irão se associar de maneira tão intensa que veremos uma militarização do clero, vista, por exemplo, na arquitetura Românica, e uma clericalização da aristocracia, nas ordens religiosas de cavalaria, formando, na primeira metade desses três séculos, o que o professor Hilário Franco Júnior chamará de sociedade Feudo-Clerical (1993). Outro ponto fundamental desses três séculos mencionados, desencadeará um processo de crescimento denominado de dinâmica da economia senhorial que teve como característica o crescimento econômico e comercial, territorial (arroteamentos, reconquista e cruzadas no oriente e norte) e um crescimento urbano.

Por muito tempo, como na obra de Pirenne (1968), se acreditou que as cidades no ocidente medieval se definharam completamente, especialmente graças ao papel dos Árabes, porém as novas descobertas históricas e arqueológicas nos mostram que apesar do seu rearranjo geográfico e diminuição da intensidade do comércio, as cidades não desaparecem. Com esse processo de dinâmica, somada a simbiose entre cidade e campo, no qual a primeira consome o produto do segundo, temos um crescimento demográfico bastante acentuado entre os séculos XI e XIII.

A Igreja medieval, chamada de grande senhora do ocidente, com certeza pode honrar este título na Idade Média Central, seja através de sua quantidade de riquezas, seja pela sua unidade ou pelo seu controle do tempo, seja o cronológico, o anual, o diário ou até os tempos da vida (2001).

Geralmente, Igreja pode significar três coisas, o edifício, a comunidade dos Cristãos (a Cristandade) ou ainda a Instituição, principalmente sobre a Igreja que tratará o quarto capítulo Igreja e sociedade (p. 81-114). Num primeiro momento, como nos mostra Cândido, a instituição nascida em Jerusalém, mas só fundada em Roma no século I se valeu de dois recursos para sua consolidação, os concílios e o monasticismo. Este fundado por volta do século IV, junto ao culto dos Santos desempenhará um forte papel na conversão das populações rurais na Antiguidade Tardia e Alta Idade Média, tendo como inspiração geralmente, a regra de São Bento, que pregava o cenobitismo total.

2 Senhorio pode ser compreendido como todos os meios que um senhor feudal tem de se apropriar do trabalho de um camponês (FRANCO JÚNIOR, 2001).

3 Strictu sensu, Feudalismo é o contrato feudo-vassálico em sí (LE GOFF, 1995). Lato sensu, é o sistema multifacetário, que irá se desenvolver na Europa Ocidental no século XI, chegará a seu auge e que morrerá no século XIII nos braços das monarquias nacionais (GUERREAU, 1980). 
Uma dessas ordens monásticas, a de Cluny, irá se destacar entre os séculos X e XI. Essa ordem pregava além de outras cosias a emancipação total da Igreja frente à Aristocracia laica, dando ignição a um movimento denominado de "Reforma eclesiástica". Esta reforma, será colocada em prática por Papas como Nicolau II, Alexandre II, Gregório VIII e Urbano II, e alguns de seus pontos foram a exigência do celibato clerical, o combate a simonia e também os aspectos que chamamos de "monarquia papal": A proeminência do Bispo de Roma (Papa), sendo que este só passaria a ser eleito por um colégio de cardeais sem interferência da aristocracia e que também a este estava restrito o direito de nomear os bispos.

A aristocracia, frente a essa perca de poderes irá reagir, e o episódio de Henrique IV, o sacro imperador romano-germânico é o mais característico. Henrique irá se recusar a acatar as disposições do papa reformador Gregório VII e será excomungado no ano de 1076, iniciando um longo conflito entre o papa e o imperador denominado de "querela das investiduras" que leva este nome, pois, a raiz do conflito se encontra no seguinte questionamento: quem deve nomear os bispos, o papa, ou o imperador? Mas, na prática, significava algo maior.

Sendo a Igreja e o Império as duas instituições universalistas do ocidente medieval o verdadeiro questionamento era: quem deve governar a cristandade? Este conflito só se resolverá em 1122, em favor da Igreja, na Concordata de Worms no qual o imperador reconhecia a soberania do papa inclusive em termos temporais. Apesar da vitória do Papa, este acabará não colocando em prática sua soberania, pois já no século XII, os Estados Nacionais estavam se unificando, portanto, o particularismo triunfara sobre o universalismo e isso vemos especialmente em dois episódios, o cativeiro de Avignon, no qual o papa por várias décadas ficou cativo na França e no Cisma do Ocidente em que mais de uma pessoa afirmara ser o sumo pontífice ao mesmo tempo.

A solução para esta cisma só veio ocorrer nos concílios de Constança $(1414$ - 18) e Florença (1438 - 45) que levará o surgimento de uma nova heresia, a conciliarista. O herege, é aquele que apesar de se dizer cristão nega um ou mais dogmas da Igreja, portanto, diferente do infiel, que é um inimigo externo, o herege é um inimigo interno. Outro importante evento decorrente da Querela das Investiduras são as Cruzadas, as famosas guerras empreendidas pelos cristãos contra os muçulmanos visando a conquista da Terra Santa e levante na qual a Igreja prometera indulgência plenária para seus participantes.

Foram oito cruzadas ao todo e se estenderam entre os séculos XI e XIII, sendo que além dos aspectos tradicionais, Cândido cita três em especial, o primeiro é o fenômeno da paz e da trégua de Deus, na qual a Igreja buscava limitar a violência aristocrática, sendo que no primeiro caso, limitar a determinados grupos (apenas contra nobres ou contra o infiel) e no segundo a determinados dias.

O segundo fenômeno se dá na importância que Jerusalém tinha para os peregrinos, e por fim, a formação da monarquia papal, no contexto de querela das investiduras, quando o Papa Urbano II convoca a primeira cruzada está colocando em prática a sua prerrogativa de governar a Cristandade.

No quinto capítulo, Crises e Renovações (p. 115-136), o autor discute os principais fatores da Crise do século XIV, caracterizada por antagonizar com o momento que a antecedeu, se entre os séculos XI ao XIII vemos uma grande prosperidade econômica e crescimento 
demográfico, no século XIV veremos uma grande mortalidade tendo três grandes aspectos, a fome, a guerra dos cem anos (1337 - 1453), e a peste.

Este período, passa a ser mais estudado na segunda metade do século XX por historiadores como Georges Duby, por exemplo. Duby, e outros, irão se interessar pela chamada "conjuntura de 1300" na qual irão encontrar uma inflexão da economia senhorial e um princípio de crise. A principal interpretação corrente para este fenômeno de crise será que graças a expansão territorial e demográfica, a necessidade de domínios aumentou, porém, quando a dinâmica atinge seu limite os recursos se tornaram escassos e os solos empobreceram, gerando uma baixa produtividade e alta dos preços em 1300 que, portanto, gerara a Grande Fome de 1315.

Cândido comenta que existiu um exagero das fontes contemporâneas para as altas de preços e que possivelmente a principal responsabilidade para este princípio de crise foram condições climáticas adversas e não uma crise generalizada da economia senhorial, que apesar dos problemas, vivia seu auge se reinventa após a crise. Apesar de praticamente cinco séculos longe da peste, a Peste Negra, através de via marítima, chega da Ásia entre 1347 e 1350 apresentando-se de três formas: a bubônica, a septicêmica e a pulmonar, sendo que a terceira, transmitida via gotícula de saliva, foi a mais mortal, de maneira que exterminara, em algumas regiões da França cerca de $70 \%$ da população.

O último aspecto desta crise as guerras nacionais do século XIV e XV como a Guerra dos Cem Anos entre a França e a Inglaterra, apesar dos problemas econômicos locais que causavam, marcam a vitória de uma instituição: o Estado nacional moderno. Este surge em torno da figura do Rei que constituíra um exército profissional permanente, uma burocracia estatal, uma moeda e sistema de taxação única, o que irá facilitar ao acúmulo de capital pelas burguesias nacionais.

O surgimento do Estado nacional é um dos principais motivo pelos quais devemos estudar História medieval, e uma das relações dessa com a contemporaneidade, uma vez que muitos países europeus que hoje conhecemos surgem nesse momento, inclusive Portugal, que dominara o Brasil entre 1500 e 1822. Para responder o questionamento de se houve ou não uma crise sistêmica no século XIV, Cândido acredita que é interessante compreender a economia medieval numa dinâmica de longa duração, algo já proposto por Jacques Le Goff e expandido por Jérôme Baschet, a chamada "Longa Idade Média" que se estende até o século XVIII tomando como parâmetro as mentalidades (2015).

Nessa perspectiva, apesar dos fatores do século XIV e XV já mencionados, isso não será suficiente para criar uma crise civilizacional completa, muito pelo contrário, como mostra Baschet, dentro da dinâmica senhorial haverá o fenômeno das grandes navegações e através dessas, o europeu alcançara o novo mundo (2006).

No último capítulo, A fabricação da Idade Média (p. 137-156), nos é colocado como que a ideia de Idade Média foi se estabelecendo com tempo, desde sua realidade Histórica até os dias de hoje. Conceito criado pelos renascentistas já com um norte pejorativo (idade do meio), foi consolidado por iluministas e até alguns historiadores pré-Annales como Jules Michelet. Se por um lado, possuímos uma herança negativa na memória coletiva sobre este período, ele vem sendo resgatado em várias ocasiões geralmente na cultura popular, muitos 
livros, jogos de computador ou RPGs são ambientados na Idade Média, mas nada se compara com o resgate feito pela historiografia.

Historiadores como Le Goff, Duby e Hilário Franco Júnior demonstraram como que este período, às vezes romantizado, mas na maioria delas, depreciado, não foi um período de trevas nem de ouro da História da humanidade. Ao contrário do livro de Jacques Heers traduzido homonimamente (1988), a obra de Cândido apenas trata do ocidente excluindo temas como, por exemplo, o mundo Islâmico e Bizantino, porém, ela consegue ser muito bem-sucedida naquilo que se propõe, um manual introdutório aos estudos de História Medieval com uma gama de leituras complementares recomendadas. Cândido com sucesso, utilizando uma bibliografia atualizada, vários documentos fundamentais e novidades da arqueologia, dar uma boa introdução para os estudos de História Medieval com suas fontes e problemas, iniciar os leitores na História acadêmica, que se difere da escolar especialmente por dois motivos, o primeiro é que a obra não utiliza de uma cronologia arbitrária, e em segundo, apesar de muitas vezes também se utilizar dos contrastes, a História escolar, tende a racionalizar a História, ou apelando para um sentido de progresso, ou ainda de "avanços e recuos" (PEREIRA \& GIACOMONI, 2008). O livro resenhado, analisa cada processo por si, dentro de várias formas de duração. Pela sua imensa quantidade de novidades, é uma boa segunda ou terceira leitura, tanto para o estudante de História medieval, para que possa dialogar com esta obra tantas outras da grande produção medievalista brasileira e estrangeira, quanto para o professor que irá trabalhar este tema em sala de aula e precisa atualizar seu repertório bibliográfico e documental para a atividade docente.

\section{REFERÊNCIAS}

BASCHET, Jérôme. A Civilização Feudal: do ano mil à conquista da América. Tradução de Marcelo Rede. São Paulo: Globo, 2006.

FLORI, Jean. Cavalaria. São Paulo: Madras, 2005.

FRANCO JÚNIOR, Hilário. Feudalismo. 1993.

FRANCO JÚNIOR, Hilário. A Idade Média: nascimento do Ocidente. São Paulo: Brasiliense, 2001. GUERREAU, Alain. O Feudalismo: Um horizonte teórico. Lisboa, Ed, v. 70, 1980.

HEERS, Jacques. História medieval. Bertrand Brasil, 1988.

LE GOFF, Jacques. A Civilização do Ocidente Medieval. Lisboa: Editorial Estampa, 1995

LE GOFF, Jacques. A história deve ser dividida em pedaços. Trad. Nícia Adan Bonatti. São Paulo: Editora Unesp, 2015.

MACEDO, José Rivair. Repensando a Idade Média no Ensino de História. In: KARNAL, Leandro (org.). História na Sala de Aula: conceitos, práticas e propostas. São Paulo: Contexto, 2005, p. 109126.

PEREIRA, N. M.; GIACOMONI, Marcelo Paniz. Possíveis passados. Representações da Idade Média no ensino de História. Porto Alegre: Zouk, 2008.

PIRENNE, Henri. História econômica e social da Idade Média. Mestre Jou, 1968.

SILVA, Marcelo Cândido da. História Medieval. São Paulo: Contexto, 2019. 160 p.

Data submissão: $16 / 04 / 2020$

Data aprovação:22/06/2020 